\title{
AÇÃO DE RODAS COMPACTADORAS DE SEMEADORAS SUBMETIDAS A CARGAS VERTICAIS NA DEFORMAÇÃ̃O DO SOLO ${ }^{1}$
}

\author{
Effect of submitted seeders press wheels under the vertical loads \\ in soil physical deformation
}

\author{
Rouverson Pereira da Silva², José Eduardo Corá ${ }^{3}$, Afonso Lopes ${ }^{2}$, \\ Carlos Eduardo Angeli Furlani ${ }^{2}$
}

\begin{abstract}
RESUMO
Uma semeadura bem realizada é fundamental para o sucesso de implantação de uma cultura e as rodas compactadoras utilizadas nessa operação devem ser capazes de melhorar o contato solo-semente para promover boa emergência das plântulas. Com o presente trabalho teve-se por objetivo estudar a influência de três modelos de rodas compactadoras submetidas a diferentes níveis de carga vertical, sobre parâmetros físicos do solo, em uma pista de ensaios projetada para essa finalidade. $O$ trabalho foi desenvolvido no município de Uberaba, MG, em LATOSSOLO Vermelho distrófico, textura média, preparado com enxada rotativa. O delineamento experimental utilizado foi o de blocos ao acaso, com 3 tratamentos e quatro repetições. Os modelos de rodas 1 e 2 apresentaram melhores coeficientes de correlação para as equações obtidas nos diagramas pressão-deformação do que a equação obtida com a roda 3.
\end{abstract}

Termos para indexação: Parâmetros físicos do solo, canal de solo, semeadura.

\begin{abstract}
The success of the establishment of a crop depends on several factors and the seeders press wheels should be capable to improve the contact soil-seed to promote good seed germination. The present work had as objective to study the influence of three models of press wheel, under different load levels on soil physical characteristic, in a projected sowing assay lane for this purpose. The experiment was carried in the municipal district of Uberaba, with, 3 blocks and four replications. The models of press wheels 1 and 2 presented better coefficients of correlation for the equations gotten in the diagrams pressure-deformation than the equation gotten with press wheel 3 .
\end{abstract}

Index terms: Soil physical parameters, soil bin, sowing.

\section{(Recebido para publicação em 6 de abril de 2004 e aprovado em 20 de abril de 2005)}

\section{INTRODUÇÃO}

O projeto de uma máquina agrícola encontra um fator complicador por se realizar na interface de diferentes sistemas, que possuem variáveis que não podem ser matematicamente bem definidas. Dessa forma, o projetista deve considerar as diversas interações entre os sistemas máquina-solo-planta.

As rodas compactadoras de semeadorasadubadoras têm por função exercer o controle de profundidade e posicionar o solo sobre a semente, além de aumentar o contato solo-semente, melhorando a absorção de água e garantindo uma melhor germinação (PACHECO, 1994). Entretanto, a influência dos diversos modelos de rodas compactadoras e sua pressão sobre o solo são fatores pouco conhecidos.

Devido ao grande número de variáveis envolvidas, a pesquisa de campo em máquinas agrícolas encontra grandes dificuldades quando se pretende relacionar a interação máquina-solo-planta. Schafer et al. (1968), estudando alguns implementos agrícolas, concluíram que a operacionalização de ensaios para interação máquinasolo em condições de campo é onerosa, difícil e demorada. Dessa forma, os canais de solo ou caixas de solo surgiram como uma ferramenta para facilitar o estudo da interação máquina-solo, como demonstram Lepore Neto \& Steffen Junior (1986), que destacam ser fundamental, durante os ensaios, manter constantes as condições de teste quanto ao solo e operação do implemento. Entretanto, os mesmos autores afirmam que não é tarefa fácil correlacionar os resultados obtidos em canais de solo com aqueles obtidos em ensaios de campo. Gomide \& Rosa (1984) ressaltaram que a versatilidade do uso de canais de solo decorre das facilidades de controle das diversas variáveis envolvidas na mobilização de solos.

Muitas são as variáveis presentes no projeto de uma semeadora e, algumas delas, como a pressão da roda compactadora e profundidade de semeadura, além de

\footnotetext{
${ }^{1}$ Parte da Tese de Doutorado do $1^{\circ}$ autor junto à FCAV/UNESP.

${ }^{2}$ Professor Doutor, Departamento de Engenharia Rural - FCAV/UNESP - Jaboticabal, SP - rouverson@fcav.unesp.br

${ }^{3}$ Professor Doutor, Departamento de Solos e Adubos - FCAV/UNESP - Jaboticabal, SP - cora@fcav.uensp.br
} 
outros fatores inerentes ao solo, como o teor de água, podem ser limitantes para a obtenção de resultados de pesquisa. Segundo Balastreire (1990), em grande parte das semeadoras disponíveis no Brasil, pode-se realizar o controle da compactação sobre a semente por meio das rodas compactadoras ou rodas de controle de profundidade. Esse mesmo autor afirma que algumas rodas possuem um alívio central na linha de semeadura ou apresentam rodas duplas em "V", para evitar a compactação excessiva sobre as sementes.

O efeito da compactação do solo na emergência das plântulas varia com o teor de água do solo e com o local de aplicação da pressão. Johnson \& Buchele (1961) e Stout et al. (1961) constataram que a compactação da superfície do solo na região da semente altera o teor de água, o comportamento térmico, a resistência mecânica e o comportamento das plantas. Stout et al. (1961) concluíram ainda que pressões aplicadas ao nível e não acima da semente melhoram a emergência das plantas.

Stefanutti (1979), trabalhando com um único modelo de roda, mudando apenas as cargas de compactação, constatou a alteração de valores para densidade e temperatura do solo em relação à profundidade, comprovando que a modificação do comportamento físico proporcionado à semente e plântulas é provocada apenas pela regulagem de carga da roda compactadora sobre o solo.

Hummel et al. (1981), trabalhando com diferentes tipos de rodas compactadoras na semeadura de soja, afirmaram que o desenho e a operação da roda compactadora apresentou considerável influência sobre o ambiente do solo em torno da semente e que essa influência depende do nível de pressão e desenho da roda, do teor de água e do tipo do solo e das condições climáticas no período entre a semeadura e a emergência.

Rainbow (2000) afirma que o perfil ideal de rodas compactadoras sempre estará por ser comercializada, e que, geralmente, rodas em forma de $\mathrm{U}$ ou $\mathrm{V}$ fornecem a pressão necessária com um mínimo de peso.

Com o presente trabalho, haverá contribuição para a realização de estudos relacionados às interações do sistema máquina-solo-planta durante a operação de semeadura, verificando o efeito de três rodas compactadoras, submetidas a diferentes níveis de cargas verticais, sobre a semente, com o objetivo de se determinar o perfil do solo e o diagrama de pressão-deformação do solo para cada modelo de roda.

\section{MATERIALEMÉTODOS}

O trabalho foi desenvolvido na Área Experimental da FAZU - Faculdades Associadas de Uberaba, localizada no município de Uberaba - MG, cujas coordenadas geográficas são: latitude de $19^{\circ} 44^{\prime} 13^{\prime \prime} \mathrm{S}$; longitude: $47^{\circ} 57^{\prime} 27^{\prime \prime} \mathrm{W}$ e altitude de $780 \mathrm{~m}$. O solo da Área Experimental é classificado como LATOSSOLO Vermelho distrófico (EMBRAPA, 1999) e a pista é constituída de sete canais de solo nivelados, delimitados por trilhos, sobre os quais desliza um trole acionado por motor elétrico.

$\mathrm{O}$ trole possui um suporte de fixação que permite $\mathrm{o}$ acoplamento das rodas compactadoras, com duas plataformas para cargas estáticas, uma delas com o centro no plano vertical contendo o eixo da roda, que recebe a carga efetiva da roda sobre o solo; a outra plataforma, localizada na extremidade oposta, recebe as cargas para neutralizar o peso próprio da roda. Dessa forma, o suporte de fixação não oferece restrições ao deslocamento vertical da roda, mas impõe restrição ao movimento de rotação horizontal, fazendo com que a roda possa deslocar-se em linha reta, acompanhando possíveis irregularidades no terreno.

O acoplamento é realizado, então, por meio de um eixo vertical deslizante com chaveta, projetado para que cada conjunto roda + eixo tivesse o mesmo peso próprio, assegurando efeitos iguais de compactação, quando usadas cargas estáticas semelhantes.

Para realização dos ensaios, foram escolhidos três modelos de rodas (FIGURA 1), classificadas de acordo com a ASAE (1995) em:

- Roda 1: roda duplo-angulada, constituída por duas rodas cilíndricas em "V", revestidas com borracha maciça, normalmente usada para plantio direto;

- Roda 2: roda convexa larga, revestida com borracha deformável;

- Roda 3: roda dupla com nervura simples em "V", constituída por duas rodas cilíndricas revestidas com borracha maciça, com nervura central.

O preparo do solo foi realizado com um escarificador de três hastes curvas, com ponteiras sem asas e espaçamento de $25 \mathrm{~cm}$, tracionado por um trator $4 \times 2$, de $47,7 \mathrm{~kW}$, a uma profundidade de $30 \mathrm{~cm}$. Em seguida, utilizouse para uniformização do solo nos canais uma enxada rotativa equipada com lâminas tipo veloz de 6 flanges, com largura útil de 1,30 m, operando com profundidade média de $15 \mathrm{~cm}$, tracionada por um microtrator de $10,8 \mathrm{~kW}$.

Ciênc. agrotec., Lavras, v. 29, n. 4, p. 839-847, jul./ago., 2005 


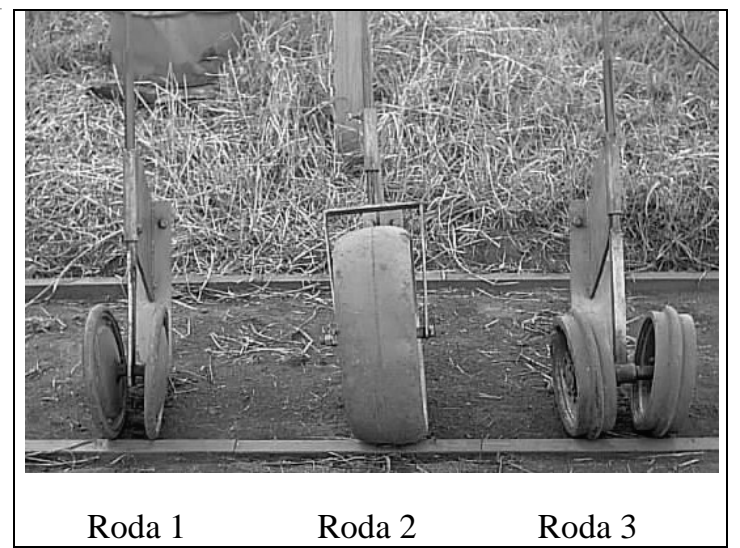

FIGURA 1 - Rodas compactadoras utilizadas.

Com o objetivo de caracterizar o preparo do solo com relação ao tamanho de agregados, foram retiradas após o preparo quatro amostras até a profundidade de preparo, segundo metodologia proposta por Gamero \& Benez (1990). As amostras foram então levadas a uma estufa a $105^{\circ} \mathrm{C}$, com circulação de ar forçada, para retirada do teor de água e propiciar resistência do solo ao peneiramento. A análise da desagregação do solo foi realizada com um conjunto de peneiras manuais, com malhas entre 1,68 e 101,60 mm, sendo analisada por meio das variáveis: porcentagem de agregados retidos por classe e tamanho, módulo de finura e diâmetro médio geométrico.

Com o solo dos canais nivelados, realizou-se o ensaio das três rodas, compactando-se faixas de $2 \mathrm{~m}$ de comprimento, separadas por um intervalo de $0,5 \mathrm{~m}$. As cargas estáticas foram variadas a cada $2 \mathrm{~m}$, de 75 a $425 \mathrm{~N}$, em intervalos de $50 \mathrm{~N}$. Nesse ensaio, procurou-se verificar a estabilidade das rodas e o perfil da linha de compactação. Foram realizadas para cada modelo de roda compactadora três observações por faixa de $2 \mathrm{~m}$.

Em seguida, utilizando-se as entre-faixas de $0,50 \mathrm{~m}$, foram aplicadas novamente as cargas de 75 a $425 \mathrm{~N} \mathrm{em}$ intervalos de $50 \mathrm{~N}$, em ensaios estáticos, com o objetivo de se determinar o perfil do solo para cada roda e o diagrama de pressão-deformação do solo. A seção transversal do solo foi avaliada por meio da utilização de um miniperfilômetro, após a aplicação de cada carga.

A determinação da pressão exercida pelas rodas compactadoras ocorreu a partir da Equação 1, descrita por Mialhe (1980), para cálculo da área de contato pneu-solo em condições de deslocamento:

$$
\mathrm{S}=1,005 \mathrm{r} b
$$
em que:

$$
\begin{array}{ll}
\text { r: } & \text { raio da roda, } \\
\text { b: } & \text { largura da roda. }
\end{array}
$$

Conhecendo-se a carga estática aplicada e a área de contato entre a roda e o solo, determinou-se a pressão exercida pelos três modelos de rodas compactadoras sobre o solo. Por meio de uma regressão potencial para os diagramas pressão-deformação, obtiveram-se, então, as equações que relacionam para cada roda a pressão exercida sobre o solo com a máxima deformação provocada. As equações foram obtidas pela expressão empírica desenvolvida por Bernstein e modificada por Bekker (1956):

$$
\mathbf{P}_{\max }=\mathbf{k} \mathbf{z}^{\mathrm{n}}
$$

em que:

$\mathbf{P}_{\max }$ : pressão máxima exercida sobre o solo,

k: coeficiente de proporcionalidade,

z: máxima deformação do solo (mm),

n: coeficiente de deformação do solo.

De acordo com Vieira (1982), os valores de $\mathbf{k}$ e $\mathbf{n}$ podem ser estimados por regressão linear ou não-linear, sendo com essa última que se obtêm melhores resultados.

\section{RESULTADOS E DISCUSSÕES}

$\mathrm{Na}$ distribuição de agregados do solo após o preparo com escarificador seguido de enxada rotativa, houve a predominância de agregados pequenos. Essa característica fica evidenciada pela presença na camada mobilizada, de 65,09\% de agregados com classe de tamanho menor que 1,18 mm e pelo Diâmetro Médio Geométrico encontrado, que foi de $0,931 \mathrm{~mm}$. Esses resultados demonstram que o solo, após o preparo, adquiriu uma condição adequada para a semeadura, conforme Braunack \& Dexter (1989) e Hadas et al. (1978). O teor médio de água do solo no momento do preparo foi de $13,9 \%$.

\section{Diagrama de pressão-deformação do solo}

Os diagramas pressão-deformação para os três modelos de rodas compactadoras, obtidos por meio de ensaio estático, são apresentados na FIGURA 2. 


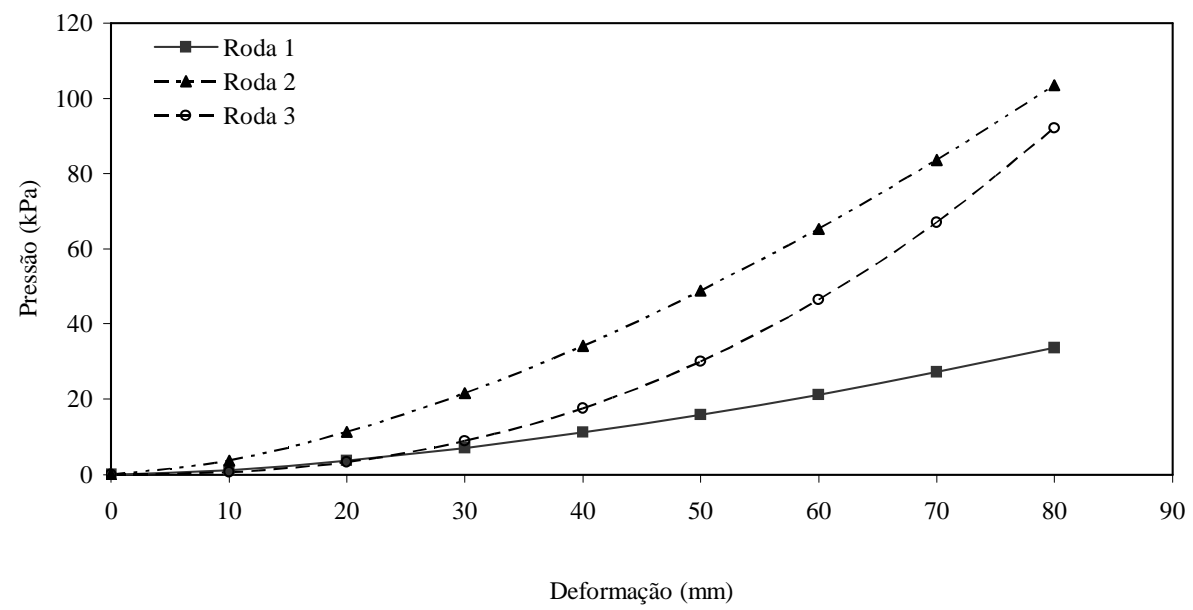

FIGURA 2 - Diagrama de pressão-deformação do solo.

Comparando-se as equações de regressão obtidas para os dados experimentais com a expressão proposta por Bernstein e modificada por Bekker (1956), pode-se determinar os coeficientes proporcionalidade $(\mathrm{k})$ e de deformação do solo (n) para a pista de ensaios. O resultado pode ser visto na TABELA 1 , na qual se observa que as equações obtidas representam melhor a deformação do solo para as rodas 1 e 2 , apresentando coeficientes de correlação bastante elevados. Já para a roda 3 o coeficiente de correlação obtido foi menor que os demais.

Bekker (1956), que determinou os coeficientes k e n a partir de uma placa plana rígida de área retangular conhecida, aplicando cargas verticais conhecidas e progressivas, afirma que os coeficientes de proporcionalidade e de deformação de um solo dependem, entre outros fatores, do tamanho da placa utilizada. Com os resultados obtidos por meio da utilização das próprias rodas compactadoras em ensaio estático, infere-se que os coeficientes determinados dependem fortemente da área de contato entre o solo e a roda e também do formato da roda compactadora. $\mathrm{O}$ fato de a roda 2 ter apresentado maior coeficiente de correlação pode ser justificado pela maior aproximação da área de contato desse modelo com a área da placa utilizada por Bekker (1956) em seus ensaios. Por outro lado, a roda 3 é a que mais se afasta do modelo, apresentando um baixo coeficiente de correlação.

Bernstein, citado por Harris (1971), afirmou que o parâmetro $\mathrm{n}$ apresenta valores entre 0 (zero) e 1 (um) para a maioria dos solos agricultáveis. Por outro lado, Mah (1980) obteve valores de $\mathrm{n}$ menores que 1 (um) para um solo arenoso de Janaúba e maiores que 1 (um) para um solo argiloso. Conforme Ashiburner \& Sim (1984), a resistência de um solo e a sua deformação por compressão ou por cisalhamento é determinada pelas resistências coesiva e friccional. Eles afirmam ainda que esses parâmetros podem sofrer variações consideráveis devido ao teor de água do solo e tamanho de agregados. Logo, diferentes valores dos coeficientes $\mathrm{k}$ e $\mathrm{n}$ podem ser encontrados devido aos vários fatores que afetam esses parâmetros, como, por exemplo, a granulometria e o teor de água do solo.

\section{Perfis do solo após a passagem das rodas compactadoras}

Nas Figuras 3, 4 e 5 são apresentados, respectivamente, os perfis do solo após a passagem das rodas 1,2 e 3, para as cargas estáticas de 75 a $475 \mathrm{~N}$, com o solo apresentando um teor médio de água de 13,9\%.

Com os perfis obtidos, demonstra-se que as rodas 1 e 3 proporcionaram uma compactação lateral do solo, ao passo que a roda 2 exerceu uma pressão de forma mais direta sobre a linha de semeadura. Pelos resultados obtidos, verifica-se também que, para a roda 1 , houve uma elevação central do solo na linha de semeadura, alterando, portanto, a profundidade de semeadura em relação àquela inicialmente idealizada. Esse efeito pôde ser observado quando da aplicação de cargas estáticas no intervalo de 75 a $325 \mathrm{~N}$. Para cargas acima de $325 \mathrm{~N}$, observou-se uma tendência de redução da elevação central até a ocorrência de uma compactação direta sobre a linha de semeadura, como pode se verificar na TABELA2. 
TABELA 1 - Valores médios dos coeficientes de proporcionalidade (k) e de deformação (n) para um LATOSSOLO VERMELHO distrófico.

\begin{tabular}{cccc}
\hline Tipo de roda & $\mathbf{k}$ & $\mathbf{n}$ & $\mathbf{r}^{\mathbf{2}}$ \\
\hline Roda 1 & 0,0321 & 1,5867 & 0,9446 \\
Roda 2 & 0,0943 & 1,5974 & 0,9902 \\
Roda 3 & 0,0027 & 2,3819 & 0,8459 \\
\hline
\end{tabular}
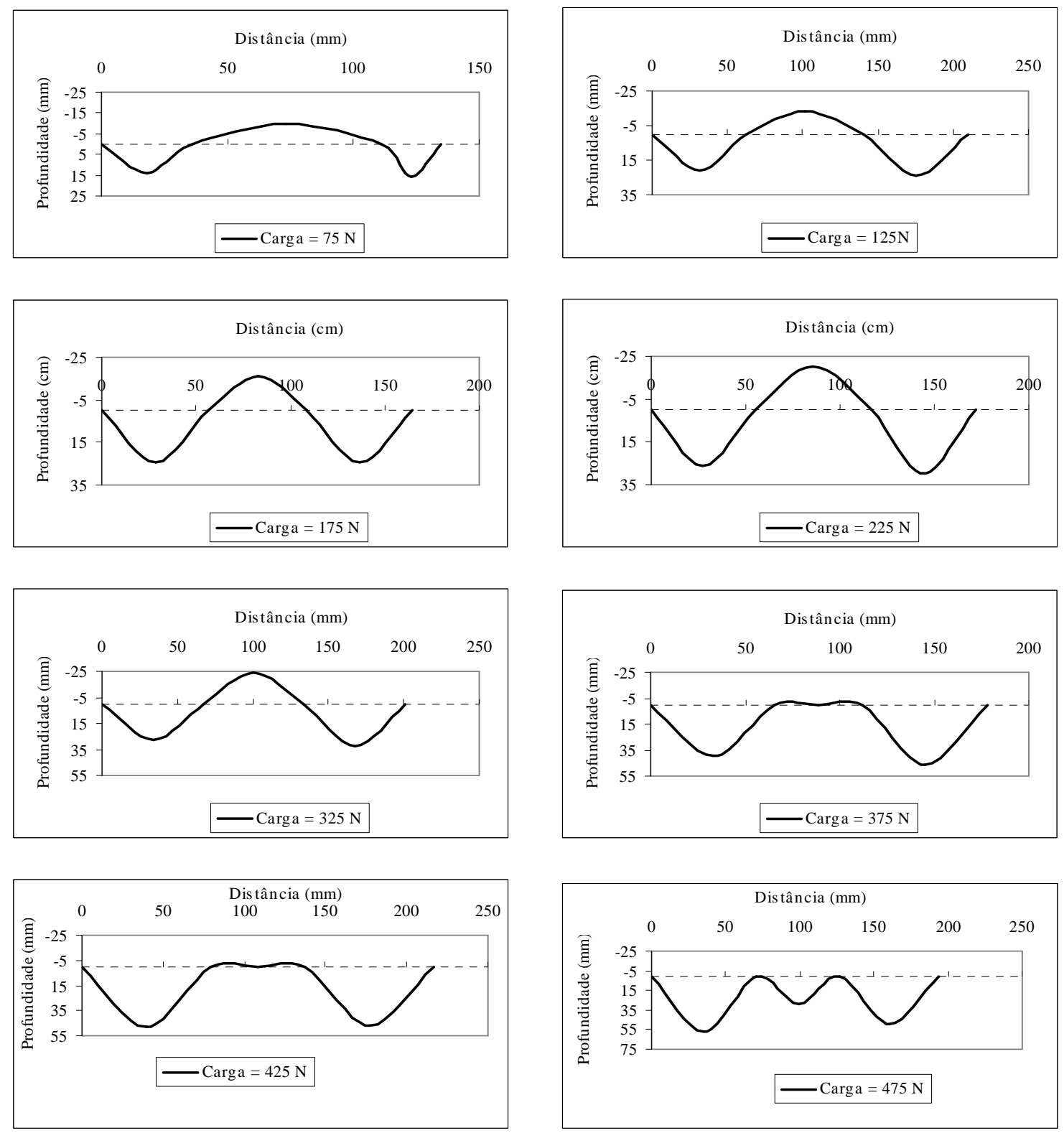

FIGURA 3 - Perfil do solo após a passagem da roda 1. 

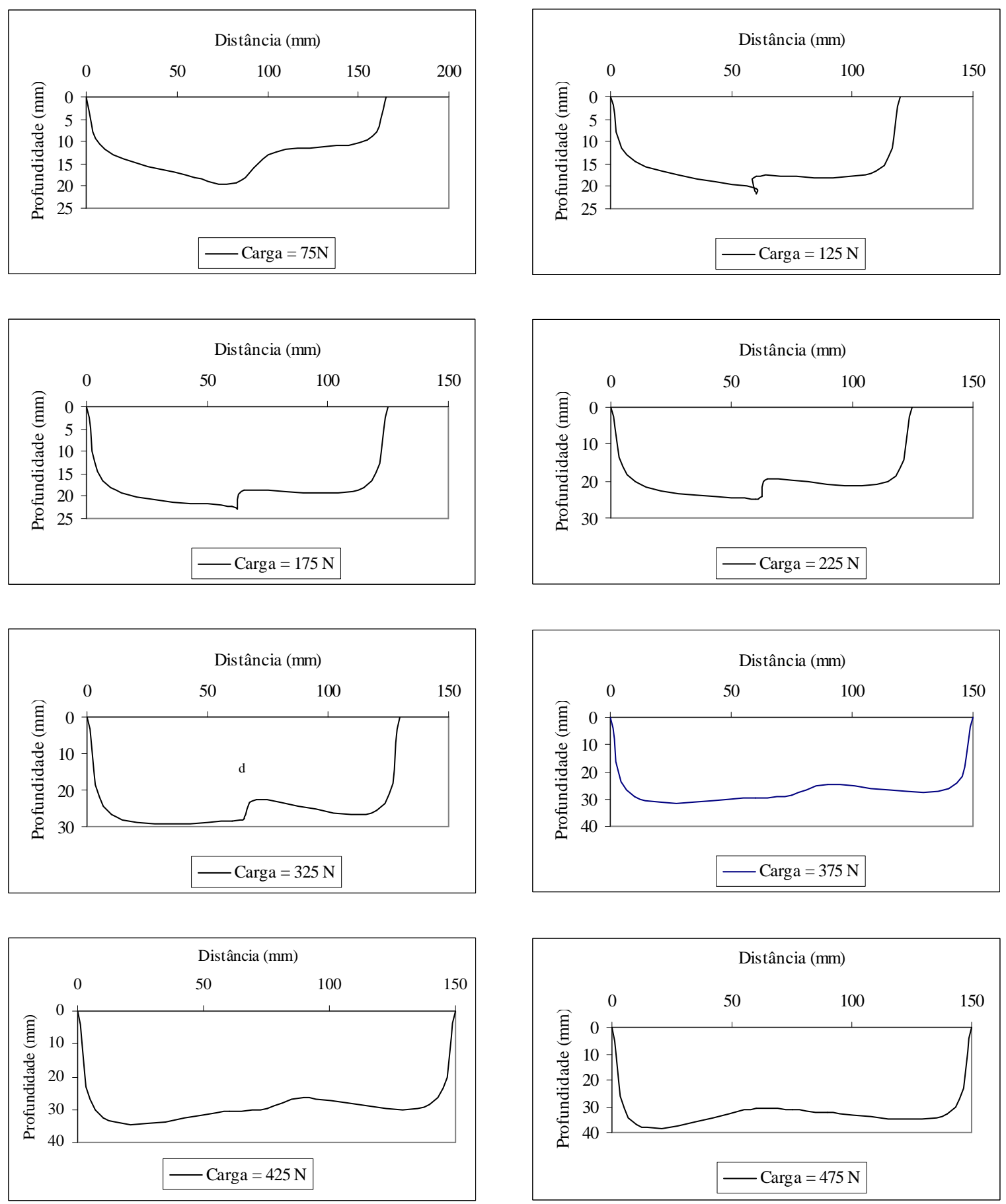

FIGURA 4 - Perfil do solo após a passagem da roda 2.

Ciênc. agrotec., Lavras, v. 29, n. 4, p. 839-847, jul./ago., 2005 

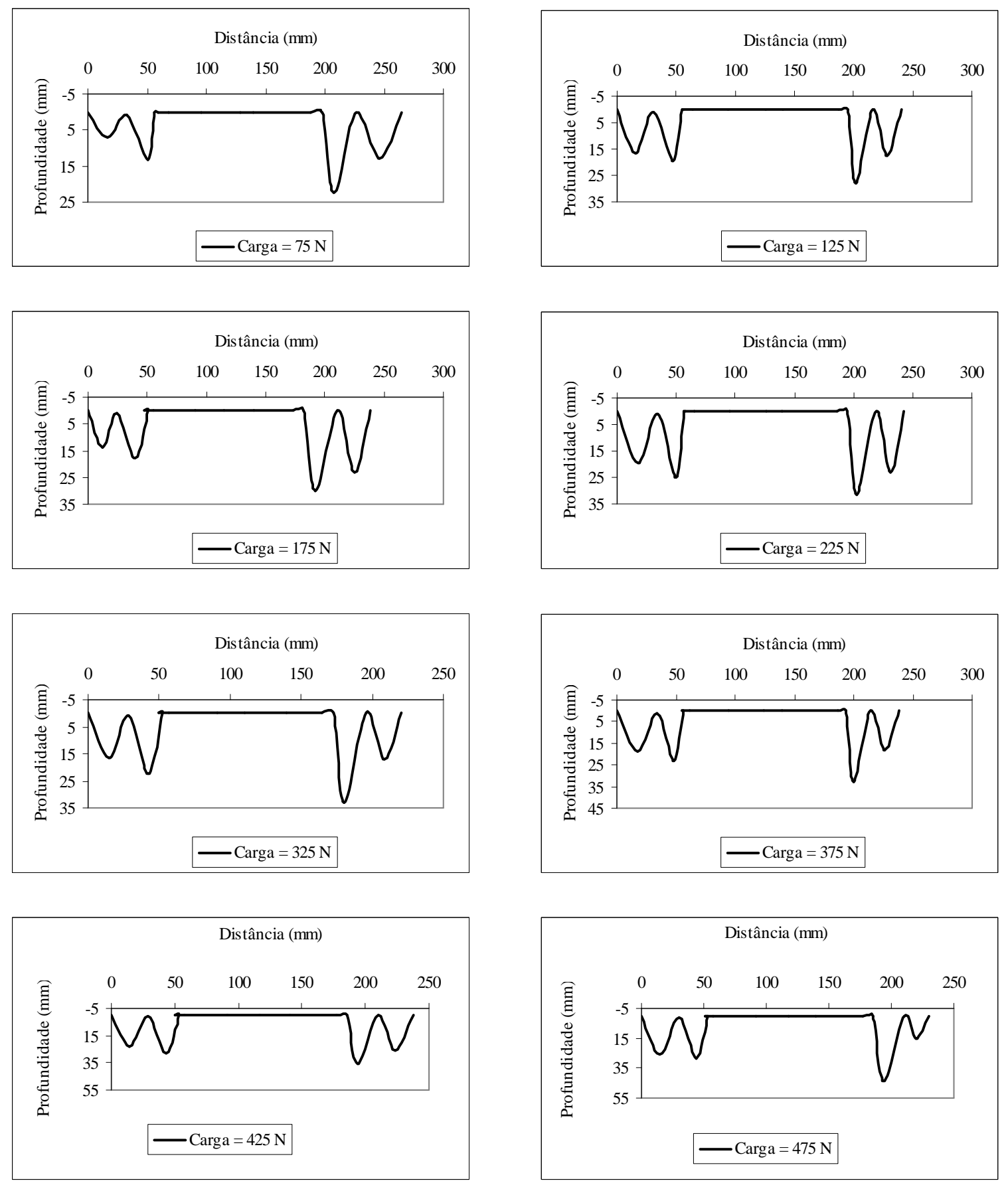

FIGURA 5 - Perfil do solo após a passagem da roda 3. 
TABELA 2 - Valores médios da elevação do solo sobre a linha de semeadura, obtidos no tratamento com a roda 1.

\begin{tabular}{cc}
\hline Carga $(\mathbf{N})$ & Elevação central (mm) \\
\hline 75 & 10,0 \\
125 & 13,0 \\
175 & 16,1 \\
225 & 20,2 \\
275 & 18,1 \\
325 & 24,4 \\
375 & 0,0 \\
425 & 0,0 \\
475 & $-28,3$ \\
\hline
\end{tabular}

Vieira (1982) afirma que a mesma pressão aplicada a solos de diferentes naturezas e teores de água provoca diferentes deformações. Mah (1980) aponta o teor de água do solo como sendo o fator que mais influi no comportamento mecânico do solo. Assim, o perfil do solo encontrado após os ensaios com a roda 1 pode se justificar por meio de três hipóteses: a regulagem inadequada da abertura entre as rodas ou o teor de água e tipo do solo.

O modelo utilizado de roda compactadora, além de não possuir regulagem de abertura das rodas, foi devidamente averiguado antes e após o uso, não se constatando nenhuma alteração da abertura entre as rodas. Portanto, pode-se atribuir o efeito de elevação central do perfil provocado por esse modelo de roda ao teor de água e ao tipo do solo. O teor de água do solo durante a realização dos ensaios foi de $13,9 \%$, sendo a textura do solo da pista de ensaios franco argilo arenoso. Em razão da natureza complexa e variável dos solos, suas propriedades não são classificadas com o grau de precisão requerido pelos materiais utilizados na engenharia, o que dificulta uma explicação mais detalhada do seu comportamento mecânico.

\section{CONCLUSÕES}

As equações obtidas nos diagramas pressãodeformação com as rodas 1 e 2 apresentaram melhores coeficientes de correlação do que a equação obtida com a roda 3 .

As rodas 1 e 3 proporcionaram uma compactação lateral do solo, ao passo que, para a roda 2 , a pressão foi exercida de forma mais direta sobre a linha de semeadura.

Para a roda 1, a aplicação de cargas estáticas no intervalo de 75 a $325 \mathrm{~N}$ provocou uma elevação central do solo na linha de semeadura. Para cargas acima de $325 \mathrm{~N}$, observou-se uma tendência de redução da elevação central, com ocorrência de compactação direta sobre a linha de semeadura.

\section{REFERÊNCIAS BIBLIOGRÁFICAS}

AMERICANSOCIETYOFAGRICULTURALENGINEERS. ASAE standard: ASAE S477 terminology for soil-engaging components for conservation-tillage planters, drills and seeders. In: Agricultural engineers yearbook of standards. Saint Joseph, 1995. p. 312-317.

ASHIBURNER, J. E.; SIM, B. G. Elementos de diseño de labranza. São José: IICA, 1984. 473 p.

BALASTREIRE, L. A. Semeadura convencional. In: . Máquinas agrícolas. São Paulo: Manole, 1990. cap. 5, p. 146-207.

BEKKER, C. F. Soil compaction pressures under rolling press wheels. Transactions of the ASAE, Saint Joseph, v. 2, n. 1, p. 63-64, 1956.

BRAUNACK, M. V.; DEXTER, A. R. Soil aggregation in the seedbed: a review II: effect of aggregate sizes on plant growth. Soil \& Tillage Research, Amsterdam, v. 14, p. 291-298, 1989. 
EMPRESA BRASILEIRA DE PESQUISA AGROPECUÁRIA. Centro Nacional de Pesquisa dos Solos. Sistema brasileiro de classificação dos solos. Brasília, 1999.412 p.

GAMERO, C. A.; BENEZ, S. H. Avaliação da condição do solo após a operação de preparo. In: SILVEIRA, G. M. (Coord.). IV ciclo de estudos sobre mecanização agrícola. Campinas: Fundação Cargill, 1990. p. 12-21.

GOMIDE, H. A.; ROSA, C. A. Simulação da interação soloferramentas agrícolas. In: CONGRESSO BRASILEIRODE ENGENHARIAMECÂNICA, 7., 1984, Uberlândia. Anais... Uberlândia: UFU, 1984. p. 257-269.

HADAS, S. A.; WOLF, D.; MEIRSON, I. Tillage implements: soil structure relationships and their effects on crop stands. Soil Science Society of America Journal, Madison, v. 42, n. 4, p. 632-637, 1978.

HARRIS, W. L. The soil compaction process. In: BARNES, K. K. (Ed.). Compaction of agricultural soils. Michigan: ASAE, 1971.p.9-44.

HUMMEL, J. W.; GRAY, L. E.; NAVE, W. R. Soybean emergence from field seedbed environments. Transactions of the ASAE, Saint Joseph, v. 24, n. 4, p. 872-878, 1981.

JOHNSON, W. J.; BUCHELE, W. F. Influence of soil granule size and compaction on rate of soil drying and emergence of corn. Transactions of the ASAE, Saint Joseph, v. 4, n. 2, p. 170-174, 1961.

LEPORE NETO, F. P.; STEFFEN JUNIOR, V. Experimental field-testing device for agricultural tools. Experimental Techniques, Bethel, v. 10, n. 8, p. 24-25, 1986.

MAH, M. M. Parâmetros físicos (Kc, Kf, n) referentes à resistência ao rolamento e suas relações com a umidade, em dois solos. 1980. 52 f. Dissertação (Mestrado em
Engenharia Agrícola, Mecanização Agrícola) - Universidade Federal de Viçosa, Viçosa, 1980.

MIALHE, L. G. Rodado e sistema de direção. In: Máquinas motoras na agricultura. São Paulo: EPU, 1980. v. 2, cap. 13, p. 189-196.

PACHECO, E. P. Avaliação de uma semeadora-adubadora de precisão com modificações no tubo condutor de sementes. 1994. 61 f. Dissertação (Mestrado em Engenharia Agrícola, Mecanização Agrícola) - Universidade Federal de Viçosa, Viçosa, 1994.

RAINBOW, R. Press wheels and their use in seedling. South Australian Research and Development Institute, Alexandria, 2000. Disponível em <http:// www.sardi.sa.gov.au/crops/farmsys/f_tillag.htm>. Acesso em: 25 jun. 2000.

SCHAFER, R. L.; BOKHOP, C. W.; LOWELY, W. G. Prototype studies of tillage implements. Transactions of the ASAE, Saint Paul, v. 11, n. 5, p. 661-664, 1968.

STEFANUTTI, R. Desenvolvimento de uma pista de ensaio e carrinho com rodas compactadoras para estudos relacionados com emergência de plântulas. 1979. $60 \mathrm{f}$. Trabalho (Graduação) - Faculdade de Ciências Agrárias e Veterinárias, Universidade Estadual Paulista, Jaboticabal, 1979.

STOUT, B. A.; BUCHELE, W. F.; SNYDER, F. W. Effect of soil compaction on seedling emergence under simulated field conditions. Agricultural Engineering, Saint Joseph, v. 42, p. 68-71, 1961.

VIEIRA, L. B. Parâmetros físicos $\left(\mathbf{k c}, \mathbf{k}_{\mathbf{f}}, \mathbf{n}\right)$ referentes à resistência ao rolamento em nove solos sob duas condições de umidade. 1982. 45 f. Dissertação (Mestrado em Engenharia Agrícola, Mecanização Agrícola) - Universidade Federal de Viçosa, Viçosa, 1982. 